\title{
POLÍTICAS DE PROVISÃO HABITACIONAL NO BRASIL: CONTRADIÇÕES E LIMITES À INTEGRAÇÃO SOCIAL
}

\section{Housing Provision Policies In Brazil: Limitations To Social Integration}

\author{
Marcos Henrique Aguiar \\ Mestre em Planejamento Urbano e Regional pela UFRJ \\ Professor Substituto Faculdade de Formação de Professores no Departamento de Geografia \\ mhaggeo@yahoo.com.br
}

Artigo recebido em 30/09/2014 e aceito para publicação em 24/11/2014

http://dx.doi.org/10.12957/tamoios.2014.13077

Resumo O presente trabalho tem como propósito recuperar a trajetória da questão habitacional no Brasil, a partir da apresentação das principais intervenções realizadas pelo Estado, com destaque para o Programa Minha Casa Minha Vida. O que se observa, ao longo do tempo, é que diante da inconsistência e das distorções das políticas públicas no campo habitacional, os segmentos sociais subalternizados e as classes trabalhadoras subassalariadas providenciaram a partir de seus próprios meios as estratégias que tornaram possível sua permanência na cidade, ainda que em condições de acentuada precarização e de vulnerabilidade da moradia.

Palavras-chave: Políticas Públicas; Habitação Social; Segregação Urbana.

Abstract This paper aims to recover the trajectory of the housing issue in Brazil, from the presentation of the main interventions by the state, highlighting the Minha Casa Minha Vida Program. What is observed, over time, is that, given the inconsistency and distortions of public policies on housing, what can be observed is that the social strata represented by the urban poor had to develop strategies to remain in the city, even in severe conditions of precariousness and vulnerability housing.

Keywords: Public Policy; Social Housing; Urban Segregation. 


\section{INTRODUÇÃO}

Existe um amplo consenso entre as inúmeras análises que tratam da questão da moradia no Brasil de que as intervenções do Estado no setor habitacional não produziram resultados satisfatórios no sentido de atender a crescente demanda decorrente do processo de urbanização vivido pelo país. Fora a questão do não atendimento da demanda propriamente dita, relacionada ao acréscimo insuficiente de novas unidades, considera-se que a urbanização brasileira gerou efeitos profundamente seletivos no que diz respeito ao acesso aos benefícios urbanos - espacialmente concentrados - pelos distintos segmentos sociais.

Desde o momento a partir do qual se pode falar da emergência de uma questão habitacional no Brasil - talvez por volta do final do século XIX - aos segmentos sociais representados pelos trabalhadores assalariados urbanos sempre recaiu a insegurança no que diz respeito ao acesso à moradia.

Algumas das mais importantes intervenções do Estado brasileiro no setor habitacional anteriores à Constituição Federal de 1988 (Institutos de Aposentadorias e Pensões-IAPs, 1937-1964; Fundação da Casa Popular-FCP, 1946-1964; Banco Nacional da Habitação-BNH, 1964-1986) por diversas razões, não produziram os resultados esperados de integração dos estratos sociais mais pobres na esfera do direito à moradia.

De qualquer forma, o que se pode depreender da longa trajetória e da persistência da problemática da moradia no Brasil é que a produção dos espaços de moradia subalternizados das cidades brasileiras, representados pelos cortiços, favelas e loteamentos periféricos está associada às ações/omissão do Estado e à dinâmica de funcionamento do mercado imobiliário. De fato, em grande medida, foram os grupos sociais excluídos que se encarregaram através de suas próprias ações, de produzir boa parte da cidade.

O Programa Minha Casa Minha Vida-PMCMV (Lei 11.977 de 7 de julho de 2009) ${ }^{1}$ embora se insira num novo contexto político, marcado pela emergência de um novo arcabouço jurídicoinstitucional ${ }^{2}$ - cujo ponto de partida é a Constituição Federal de 1988 - tem apontado, considerando o caso do Rio de Janeiro, para uma tendência de reprodução e/ou expansão das áreas periféricas urbanas. O referido Programa em sua modalidade de mercado é operacionalizado a partir de uma lógica comandada pelas empresas privadas do setor imobiliário, o que tem deixado pouca margem de decisão e de influência ao poder público quanto aos rumos da implantação dos empreendimentos.

Do ponto de vista metodológico, o presente trabalho apoia-se na literatura especializada na discussão e análise da temática urbana e na consulta às fontes documentais de órgãos públicos vinculados à questão urbana e habitacional, particularmente o Ministério das Cidades. Embora no presente trabalho sejam mencionadas as três faixas de atendimento conforme definição da Lei que institui o PMCMV, procuramos manter o foco da presente análise na chamada faixa 1 do Programa, destinada ao atendimento às famílias com renda de até $\mathrm{R} \$ 1.600,00$ (mil e seiscentos reais) $^{3}$. Essa 
escolha se justifica em virtude do fato do déficit habitacional brasileiro se concentrar justamente nos segmentos sociais de baixa renda (Fundação João Pinheiro, 2008), incapazes de acessar o bem moradia pela via do mercado.

\section{MODERNIZAÇÃO ECONÔMICA E ACIRRAMENTO DAS CONTRADIÇÕES URBANAS}

A questão relacionada ao déficit e à qualidade das moradias destinadas à população urbana mais pobre já é bastante antiga. Se retrocedermos no tempo e considerarmos, a título de exemplo, o Rio de Janeiro e São Paulo, a questão da moradia popular emerge a partir da segunda metade do século XIX, devido ao acentuado crescimento populacional nessas cidades. Referindo-se a São Paulo, Bonduki (2004) afirma que surgiram nesta cidade, várias modalidades de produção da moradia destinadas aos setores de média e baixa renda, organizadas pelos agentes privados num contexto onde vigorava uma concepção liberal do Estado, vigente até $1930^{4}$.

Dentre essas modalidades, as casas de vilas e avenidas, mais higiênicas e confortáveis, eram inacessíveis aos trabalhadores mais pobres, lhes restando os cortiços, construções que, devido ao processo de adensamento tornaram-se insalubres e deterioradas. Pelo menos até as décadas iniciais do século XX, essas eram ainda as tipologias predominantes de moradia, enquadradas dentro do chamado sistema rentista, de mercado, modalidade que se estende aproximadamente até o início da Era Vargas, ocasião em que o Estado toma para si a responsabilidade pelo provimento habitacional da classe trabalhadora, através da criação das carteiras dos Institutos de Aposentadorias e Pensões-IAPs ${ }^{5}$.

É importante ressaltar que embora a década de 30 inaugure um período de intervenção do Estado na produção habitacional numa escala mais ampla através dos IAPs, autores como Oliveira e Fernandes (2010), consideram como experiência realmente pioneira na produção da moradia social, o projeto idealizado pelo presidente Marechal Hermes da Fonseca no início do século XX. Tratava-se de uma grande vila operária situada no subúrbio de Marechal Hermes na cidade do Rio de Janeiro, dotada de infraestrutura completa, serviços e equipamentos urbanos, inaugurada em $1^{\circ}$ de maio de 1914 (OLIVEIRA e FERNANDES, 2010, p. 75). Após essa primeira intervenção estatal, somente no final dos anos 30 é retomada a política de habitação social, através da instituição das carteiras prediais dos Institutos de Aposentadoria e Pensões.

Dos primórdios da industrialização brasileira até os anos 30, além da produção rentista, a demanda por novas moradias pôde ser também atendida por iniciativa das próprias empresas industriais por meio da construção de vilas operárias, solução viável enquanto se manteve relativamente reduzido o contingente de trabalhadores urbanos. Entretanto, na medida em que se intensificou o processo de industrialização e de urbanização, as empresas privadas passaram a transferir para os trabalhadores os custos relacionados à moradia e às despesas de transporte. Surge então no cenário urbano aquilo que, segundo Kowarick (1979), passou a ser designado de periferias, aglomerados afastados das áreas mais centrais, desprovidos de infraestrutura, locais de moradia de 
uma mão de obra sub-remunerada, necessária ao funcionamento e à acumulação do sistema econômico implantado (KOWARICK, 1979; LAGO, 2000). Paradoxalmente, a consolidação de uma economia de base urbano-industrial no Brasil se fez acompanhada de um processo de extrema exploração e de espoliação da classe trabalhadora, que passou a solucionar seu problema de moradia recorrendo principalmente ao processo de autoconstrução e, portanto, fora da esfera do consumo, prática inerente à mercantilização da economia.

Reforçando o argumento anterior, Lago e Ribeiro (1996) ressaltam a falta de respostas mais consistentes por parte do Estado, fazendo com que uma parcela significativa da população urbana fosse obrigada a resolver por conta própria a questão de como morar. Uma das soluções encontradas foi a produção informal/autoconstrução, que se constituiu ao longo das décadas do século passado na forma predominante de acesso à moradia (LAGO e RIBEIRO, 1996).

Apenas para ilustrar, a informalidade habitacional nas áreas urbanas do país chegou atingir mais de 50\% das construções nas grandes cidades brasileiras, uma situação que ocorreu às margens das legislações de uso, parcelamento e ocupação do solo, leis de zoneamento e de edificação. Na verdade somente parte da cidade, a chamada cidade formal, se tornou objetivo de regulação por parte do Estado, via adoção de uma série de mecanismos de ordenamento e uso do solo urbano (MARICATO, 1996) de forma a balizar o funcionamento do mercado imobiliário. É importante lembrar que enquanto surgia e se consolidava a moderna produção capitalista da moradia entre as décadas de 40 e 60, através do sistema de incorporação imobiliária - responsável pelo processo de verticalização nas cidades e cuja produção se destinava fundamentalmente aos setores sociais de maior poder aquisitivo afirmava-se de maneira crescente o seu oposto, a produção informal, representada pelas formas de moradia destinadas aos trabalhadores impedidos de ingressar no mercado imobiliário formal.

De acordo com Milton Santos (1993), desde a década de 50, acrescendo-se ao crescimento demográfico, um contingente cada vez maior da população brasileira vai se instalar nas cidades de maior porte, principalmente São Paulo e Rio de Janeiro, sinalizando para um processo de metropolização, fortemente associado com o agravamento das condições de pobreza (SANTOS, 1993, p. 10).

O modelo de planejamento urbano e regional adotado e a institucionalização das áreas metropolitanas nos anos 70 tiveram por objetivo alcançar uma distribuição mais equilibrada da população pelo território nacional. Porém, o modelo de organização da economia adotado ampliou significativamente a migração em direção às grandes cidades, gerando "Desenraizamentos, massificação e segregação...” (RIBEIRO, 1996, p. 25), situações recentes que ajudam a explicar o aumento dos níveis de pobreza e de exclusão em cidades como São Paulo e Rio de Janeiro.

O que se deduz dessa análise, é que o Estado deixou de cumprir seu papel no atendimento das demandas e necessidades de reprodução social dos trabalhadores, e estes, por sua vez, imprimiram a marca de suas ações na produção de boa parte da materialidade urbana através do processo de autoconstrução, aquilo que Maricato (1982) chamou de "arquitetura possível", referindo-se aos 
assentamentos urbanos construídos pela própria classe trabalhadora. É principalmente por meio da autoconstrução que a população urbana mais pobre soluciona seu problema de moradia - e não através dos programas e políticas habitacionais oficiais - destinando tempo seja nas horas de folga e mesmo nos finais de semana, num processo que pode se arrastar por muitos anos (MARICATO, 1982, p. 73).

Mesmo uma experiência de intervenção pública de grande porte, como foi o caso da atuação do Banco Nacional de Habitação-BNH, não foi capaz de equacionar de forma adequada as necessidades habitacionais no país. Durante a vigência do Sistema Financeiro da Habitação, o Estado promoveu a produção de uma quantidade nada desprezível de moradias. Entre 1964 e 1986, ano em que o BNH foi extinto, o Estado promoveu o financiamento de aproximadamente quatro milhões de moradias por meio do Sistema Financeiro da Habitação-SFH, expressando uma notável capacidade de intervenção no espaço urbano. Embora não se desconsidere a persistência do déficit habitacional, o governo federal instituiu um conjunto de mecanismos institucionais e financeiros que tornaram possível a produção em larga escala de moradias destinadas à população de baixa renda (ARRETCHE, 2000).

Entretanto, os dilemas e impasses relacionados à questão da moradia popular são reforçados a partir da criação do SFH, uma vez que seu formato institucional direcionava seus investimentos principalmente para as classes médias, à custa dos juros subsidiados do Fundo de Garantia por Tempo de Serviço-FGTS. Do total dos recursos do FGTS disponibilizados para o financiamento de novas moradias até o final da década de 80 , cerca de $65 \%$ foram destinados ao atendimento das camadas de renda média e alta (AZEVEDO e ANDRADE, 1982).

Assim, ao focalizar suas prioridades sobre os estratos de renda mais elevada, que representavam uma demanda efetiva para os imóveis produzidos, o $\mathrm{BNH}$ promoveu um grande crescimento imobiliário, que acabou por gerar efeitos multiplicadores bastante relevantes. No entanto, devido às limitações salariais, o financiamento às camadas mais pobres mostrou-se mais problemático, ao mesmo tempo em que gerou elevada inadimplência entre os setores que tiveram acesso ao financiamento. A falta de subsídios combinada ao arrocho salarial, diante do preço elevado da moradia e do imperativo de correção real dos débitos, são elementos responsáveis pela ineficácia do $\mathrm{BNH}$, e que contribuíram para a expansão da favelização e das periferias urbanas (AZEVEDO, 1988; CARDOSO, 2003).

Nesse sentido, o desempenho da política de habitação empreendida pelo BNH evidencia que o que realmente prevaleceu foi o privilegiamento da rentabilidade do sistema, em detrimento dos objetivos sociais. Provavelmente a crítica central a ser feita à atuação do BNH como órgão formulador e condutor da política urbana e habitacional no Brasil, foi sua incapacidade de atender a população de baixa renda, objetivo que justificou sua criação.

Mais dois aspectos da atuação do BNH merecem observação, considerando seu papel como órgão central da política de desenvolvimento urbano no país. O primeiro refere-se a não adoção de mecanismos capazes de conter o aumento dos preços dos terrenos urbanos como consequência do aumento da sua demanda para fins de produção habitacional, o que acabou por influenciar o padrão de 
localização dos conjuntos habitacionais, normalmente mais distante e periférico (ROLNIK et alii, 2013). O segundo aspecto, que seria inerente à própria concepção de operacionalização do BNH, diz respeito às concessões feitas pelo Banco aos agentes privados, como por exemplo, o repasse dos recursos financeiros (FGTS) e a transferência das decisões referentes à localização e a construção das moradias (BOLAFFI 1982).

Acreditamos que algumas das características presentes no modelo de política do BNH estejam identificadas no Programa Minha Casa Minha Vida em sua modalidade de mercado, conforme vemos a seguir.

\section{A CONSTUTIÇÃo FEDERAL DE 1988 - UM PONTO DE INFLEXÃo NA POLÍTICA URBANA}

Após a extinção do BNH em 1986 e a transferência de suas atribuições para a Caixa Econômica Federal, a política habitacional e urbana no Brasil passaria por um longo período de indefinição. Somente a partir da Constituição Federal de 1988, emerge um novo arranjo institucional e jurídico mais favorável e um novo modelo de política urbana, fruto da mobilização social que antecedeu e sucedeu o processo constituinte, referenciada no ideário da reforma urbana (SANTOS JUNIOR, 1995).

Consideramos que a Constituição Federal 1988 representa de fato um momento de inflexão em relação à política habitacional e de desenvolvimento urbano, na medida em que incorpora no âmbito da lei boa parte da agenda reivindicatória dos movimentos sociais em torno do direito à cidade. Um dos desdobramentos mais importantes da pressão popular foi a aprovação do Estatuto da Cidade (Lei 10.257 de 10 de julho de 2001), que estabeleceu os instrumentos de regulamentação do uso do solo urbano, e a definição da função social da cidade e da propriedade urbana.

Com a criação do Ministério das Cidades em 2003 se redefine a política nacional de desenvolvimento urbano, buscando inclusive preencher o vazio institucional deixado desde a extinção do SFH/BNH. Referenciado nos princípios e nos instrumentos do Estatuto da Cidade, o Mcidades procurou consolidar um novo formato institucional no campo da política urbana condizente com as reivindicações históricas dos movimentos sociais defensores do ideário da reforma urbana.

Pode-se mesmo dizer que em ultima instância o Programa Minha Casa Minha Vida é herdeiro de uma nova concepção de política habitacional, uma vez que a sua formulação e seu lançamento se encontram, de alguma forma, referenciados nessa nova conjuntura político-institucional, conforme já referida. No entanto, a despeito dos avanços jurídicos e institucionais alcançados, caberia indagar em que medida tem se avançado efetivamente na produção de um modelo de cidade que seja menos segregador e excludente, conforme reconhecimento do próprio Ministério das Cidades (CADERNOS MCIDADES, 2004).

O Programa Minha Casa Minha Vida ${ }^{6}$, lançado em 2009 sob o argumento de equacionar o 
$\overline{\text { déficit habitacional brasileiro }{ }^{7} \text {, estimado em sete milhões de unidades é considerado o carro-chefe da }}$ atual Política Nacional de Habitação, uma vez que a produção de novas unidades se faz basicamente por meio desse Programa. Em sua variante de mercado, que contempla três faixas de renda, as empresas privadas do ramo imobiliário exercem um papel de centralidade na elaboração dos projetos, na compra do terreno e na escolha da localização dos empreendimentos, em detrimento do poder público, que desempenha apenas funções de apoio ao capital privado (FIX e ARANTES, 2009).

O que se observa é que, na operacionalização do Programa Minha Casa Minha Vida, tem havido uma convergência entre faixa de mercado a ser atendida e localização dos empreendimentos. No caso da faixa 1 do Programa, cujo público-alvo são as famílias de renda entre 0 e 3 salários mínimos, vem se verificando uma tendência de reforço de velhas políticas segregacionistas em áreas carentes de infraestrutura, serviços públicos e equipamentos urbanos, além do comprometimento da mobilidade urbana. Grande parte dos empreendimentos destinados às famílias de baixa renda tem sido localizada em áreas periféricas, conforme vem acontecendo, por exemplo, na Área de planejamento 5-AP5 na cidade do Rio de Janeiro ${ }^{8}$ (CARDOSO e ARAGÃO, 2013).

De fato, uma consulta aos dados estatísticos da Secretaria Municipal de Urbanismo da Prefeitura do Rio de Janeiro referentes ao PMCMV nos oferece uma visão clara do padrão de localização que vem se delineando na cidade do Rio de Janeiro (Prefeitura da Cidade do Rio de janeiro/SMU, 2014). Não é difícil perceber a convergência entre faixa de atendimento dos beneficiários do Programa e localização dos empreendimentos. O segmento de mercado de 0 a 3 salários mínimos encontra-se sobre-representado nas áreas mais distantes da cidade, conforme já mencionadas acima. Já as faixas de renda mais altas beneficiadas pelo Minha Casa Minha Vida vem sendo contempladas com localizações mais adequadas e menos distantes, como por exemplo o bairro de Jacarepaguá.

Articulado a essa questão, Bonduki (2009) ressalta a desconsideração do PMCMV com as propostas e intenções contidas no Plano Nacional de Habitação-PLANHAB (MINISTÉRIO DAS CIDADES, 2013), que definiu um conjunto de medidas de longo prazo para servir de base para a implementação da política habitacional em âmbito nacional. Assim, as diretrizes e ações referentes à política fundiária e urbana contidas no PLANHAB, em particular aquelas relacionadas com a questão da localização adequada, não vem sendo contempladas no Programa Minha Casa Minha Vida.

A lógica de rentabilidade buscada pelas empresas construtoras tenderá, a menos que se reveja o formato desse modelo de política, a promover um processo de periferização nas cidades brasileiras (CARDOSO et alii, 2011). A redução do custo de produção das unidades habitacionais e a busca por terrenos mais baratos em áreas mais distantes dos núcleos urbanos, certamente são estratégias a que as empresas recorrem como forma de alcançar a maximização da rentabilidade.

Após cerca de dez anos de aprovação do Estatuto da Cidade, ainda são incipientes as experiências de acionamento dos instrumentos de política fundiária que teriam por objetivo a regulação do uso do solo urbano (NAIME, 2010; SANTOS e MONTANDON, 2011). Há instrumentos 
no Estatuto que permitem, por exemplo, a identificação nos planos diretores de terrenos em áreas urbanas centralizadas e infraestruturadas destinadas aos programas de habitação de interesse social. No entanto, certamente questões de ordem política, em virtude dos interesses privados envolvidos, dificultam a adoção de mecanismos capazes de impor limites aos processos de acumulação urbana, historicamente arraigados no Brasil.

O processo de valorização do solo urbano e a apropriação das rendas fundiárias têm implicações diretas no processo de estruturação da cidade e de distribuição da população no espaço urbano. Paul Singer (1982) afirma que a renda fundiária nada mais é do que o preço cobrado pelo acesso a um bem que é condição para a realização das atividades urbanas. Porém, seja para fins de uso econômico, seja para fins de uso residencial, o fator solo/localização torna-se objeto de disputa entre os diversos agentes atuantes no espaço urbano. A formação dos preços de cada parcela da terra urbana tem, portanto como ponto de partida a localização e sua posição relativa à totalidade do espaço urbano (CARLOS, 2009).

Obviamente os agentes econômicos e os segmentos sociais mais influentes têm maior capacidade de impor seus interesses em relação à acessibilidade e consequentemente aos benefícios urbanos - muitas vezes providenciados pelo Estado - quando comparados à população urbana mais pobre. Daí a importância de se aplicar os instrumentos de regulação urbana, boa parte deles já inscrita nos Planos Diretores Municipais, necessitando apenas de regulamentação.

\section{CONSIDERAÇÕES FINAIS}

Conforme vimos, são recorrentes, ao longo da história brasileira, as práticas de discriminação e de expulsão dos desvalidos da sociedade de seus espaços de moradia, principalmente a partir das ações do próprio Estado. Basta lembrar, para citar alguns exemplos, a Reforma Pereira Passos no início do século XX, cujas obras de melhoramentos, de embelezamento e de renovação urbana, resultaram no processo de desapropriação e de demolição dos cortiços da área central da cidade do Rio de Janeiro, resultando no deslocamento da população ou para os subúrbios ou para os morros próximos (ABREU, 2008). Outro exemplo, um pouco mais recente, foi a política de remoção de favelas implementada também na mesma cidade pelo Estado na década de 70, como forma de "varrer" do cenário urbano os constrangimentos à valorização do capital imobiliário. A política de remoção na cidade do Rio de Janeiro encontrou forte resistência por parte dos moradores das favelas, sobretudo em virtude da perda da acessibilidade aos locais de trabalho, o que fez com que grande parte dos removidos retornasse para as proximidades de seus antigos locais de moradia (VALLADARES, 1978).

A intenção de remover ou afastar a população pobre de determinados locais é sempre política, já que por detrás dos discursos aparentemente bem intencionados dos agentes hegemônicos, o que está em questão é sempre a intenção de deslocar os grupos sociais mais pobres para outros locais, via de regra mais distantes, com o propósito de liberar determinadas áreas para futura valorização ou novos 
usos (CAMPOS, 2012).

Para finalizar, os programas oficiais desenhados pelo Estado brasileiro para solucionar a questão habitacional nas áreas urbanas ou não foram capazes de atender a crescente demanda por novas moradias, ou promoveram a segregação espacial. O PMCMV, pacote habitacional que conta com um volume de créditos e subsídios provavelmente sem precedentes na história do país corre o risco de reproduzir os erros e fracassos de intervenções anteriores, como foi o caso do BNH. Conforme vimos, o formato institucional do Minha Casa Minha Vida transfere para o setor empresarial as decisões mais importantes na execução do Programa.

O PMCMV está fortemente ancorado no mercado, restando ao poder público pequena margem de decisão no que diz respeito ao processo de implantação dos empreendimentos. Fora isso, a exemplo do Sistema Nacional de Habitação de Interesse Social-SNHIS e do Fundo Nacional de Habitação de Interesse Social-FNHIS, a implantação do Programa não vem adotando canais de participação da sociedade civil, que permitiriam influenciar as decisões e os rumos da política habitacional atual.

Tudo leva a crer que o problema da terra tem se convertido - aliás, tem se mantido - como um dos obstáculos para a efetivação de um novo formato de política urbana. Por conta disso, o PMCMV tem sido implementado sem a devida correspondência com uma política urbana de caráter mais integrado, de forma a permitir a configuração de um novo modelo de cidade, menos desigual e excludente no que diz respeito ao acesso aos benefícios urbanos. Conforme afirmação de Milton Santos, a questão da pobreza e da exclusão urbana não decorre apenas do padrão econômico implantado no país há décadas, mas também do modelo espacial (SANTOS, 1993, p. 10). Nesse sentido, como vimos afirmando no presente trabalho, acreditamos que o Minha Casa Minha Vida, a despeito de combater o déficit habitacional, venha contribuindo para a reprodução do processo de periferização na cidade do Rio de Janeiro.

Consideramos que três ordens de fatores, atuando de forma articulada, dão a tônica do modelo habitacional implantado atualmente na cidade. Em primeiro lugar, o protagonismo exercido pelo setor privado em relação às decisões de compra dos terrenos e consequentemente da definição da localização dos empreendimentos. Em segundo lugar, a falta de acionamento dos instrumentos de regulação urbana, tal como expressos no Estatuto da Cidade. E por fim o papel coadjuvante atualmente desempenhado pelo poder público, um mero facilitador das ações privadas. Nesse sentido, seria de fundamental importância resgatar o papel do poder público como condutor na implantação dos empreendimentos do PMCMV, uma vez que o padrão predominante de localização que vem sendo adotado nas áreas priorizadas - em locais distantes com infra-estrutura insuficiente e com carência de equipamentos urbanos - reforça o modelo de cidade segregada. 


\section{NOTAS}

1-O Programa Minha Casa, Minha Vida tem por finalidade estabelecer mecanismos de incentivo à produção e aquisição de novas unidades habitacionais ou requalificação de imóveis urbanos e rurais, direcionadas à famílias com renda mensal de até $\mathrm{R} \$ 4.650,00$ (quatro mil, seiscentos e cinquenta reais), compreendendo subprogramas seguintes: o Programa Nacional de Habitação Urbana - PNHU e o Programa Nacional de Habitação Rural - PNHR. Ver: Lei 11.977 de 7 de julho de 2009, Art. $1^{\circ}$

2- Aqui merece destaque a aprovação da Emenda Constitucional nº26/2000, que reconhece o direito à moradia; a aprovação da Lei no 10.257/2001, que regulamenta o capítulo da política urbana; a criação do Ministério das Cidades em 2003 e a aprovação da Lei no 11.124/2005 que institui o Sistema Nacional de Habitação de Interesse Social-SNHIS e cria o Fundo Nacional de Habitação de Interesse Social-FNHIS. Ver: AGUIAR, M. H. de. O Fundo Nacional de Habitação de Interesse Social: Avanços e limites na perspectiva da reforma urbana. Rio de Janeiro: UFRJ/IPPUR. Série Estudos e Debates, $n^{\circ} 8$, novembro, 2008, p. 24-27).

3- De acordo a Lei que institui o Programa Minha Casa Minha Vida, três faixas de atendimento ou de mercado devem ser contempladas na aquisição das unidades produzidas, prevendo-se níveis diferenciados de concessão de subsídios segundo a faixa de renda dos beneficiários. Considera-se como prioritária a faixa 1 do Programa, destinada ao atendimento dos beneficiários cuja renda familiar não ultrapasse $\mathrm{R} \$ 1.395,00$ (três salários mínimos) faixa esta contemplada com subsídios praticamente integrais. Ver: Lei 11.977 de 7 de julho de 2009.

4- Dentre essas formas de moradia produzidas pelo capital privado, o autor destaca o cortiço-corredor, o cortiço-casa de cômodos, os vários tipos de vilas e as casas geminadas. Para maiores detalhes, ver: BONDUKI, N. Origens da habitação social no Brasil: Arquitetura moderna, lei do inquilinato e difusão da casa própria. São Paulo: Estação Liberdade, 2004, p. 43).

5- A principal crítica a ser feita aos IAPs, espécie de sistema rentista estatal, reside no seu caráter essencialmente corporativista, uma vez que o acesso ao imóvel financiado estava restrito aos trabalhadores vinculados ao sistema de previdência social de categorias profissionais específicas ver: BONDUKI, N. Origens da habitação social no Brasil: Arquitetura moderna, lei do inquilinato e difusão da casa própria. São Paulo: Estação Liberdade, 2004, p. 109).

6- O Programa Minha Casa Minha Vida contempla duas modalidades de promoção da habitação de interesse social: a promoção realizada pelas empresas construtoras, modelo de mercado claramente dominante e a promoção realizada pelas cooperativas e entidades sem fins lucrativos através do modelo de autogestão. Ver: FIX, M.; ARANTES, P.F. Como o governo Lula pretende resolver o problema da habitação. Jurdiaí: Human Rights in Brazil, 2009, p. 2.

7- O conceito de déficit habitacional refere-se tanto ao quantitativo de moradias que necessitam ser repostas em virtude da depreciação do estoque (déficit por reposição de estoque) quanto daquelas que precisam ser construídas em função de componentes como a coabitação familiar, o peso excessivo do 
aluguel e o adensamento excessivo do imóvel (déficit por incremento de estoque). A inadequação de moradias refere-se aos domicílios que não apresentam condições desejáveis, que embora não necessitem ser repostos, interferem negativamente na qualidade de vida dos moradores. Para maiores detalhes a respeito da metodologia utilizada pela FJP ver: Fundação João Pinheiro: Déficit Habitacional no Brasil, 2008.

8- A AP5 é composta por Bangu, Realengo, Campo Grande, Guaratiba e Santa Cruz, bairros-sede de suas respectivas RAs, totalizando 21 bairros (Rio de Janeiro (Cidade). Ver: Portal Eletrônico da Prefeitura Municipal do Rio de Janeiro.

\section{REFERÊNCIAS BIBLIOGRÁFICAS}

ABREU, Maurício. Evolução urbana do Rio de Janeiro. $4^{\text {a }}$ ed. Rio de Janeiro: IplanRio/Prefeitura do Rio de Janeiro, 2008.

AGUIAR, M. H. O Fundo Nacional de Habitação de Interesse Social: Avanços e limites na perspectiva da reforma urbana. Rio de Janeiro: UFRJ/IPPUR. Série Estudos e Debates, nº 8, novembro, 2008 .

ARRETCHE, Marta T. S. Estado federativo e políticas sociais: Determinantes da descentralização. Rio de janeiro: Revan; São Paulo: FAPESP, 2000.

AZEVEDO, Sérgio. Habitação e poder. Rio de Janeiro: Zahar, 1982.

- Vinte e dois anos de política habitacional popular (1964-86): Criação, trajetória e extinção do BNH. Revista de Administração Pública, Rio de Janeiro, 22(4), p. 107-119, out.- dez. 1988.

BOLAFFI, G. Habitação e urbanismo: O problema e o falso problema. In: MARICATO, E. (Org.). A produção capitalista da casa (e da cidade) no Brasil industrial. São Paulo: Alfa-Omega, 1982, p. 37-70.

BONDUKI, Nabil. Origens da habitação social no Brasil: Arquitetura moderna, lei do inquilinato e difusão da casa própria. São Paulo: Estação Liberdade, 2004.

Do Projeto Moradia ao Programa Minha Casa Minha Vida. Teoria e Debate, v. 82, 2009.

BRASIL. Lei $\mathrm{n}^{\circ} 10.257$ de 10 de julho de 2001. Presidência da República. Casa Civil Subsecretaria para Assuntos Jurídicos.

MINISTÉRIO DAS CIDADES. Cadernos Ministério das Cidades 4: Política Nacional de Habitação. Brasília, 2004.

. MINISTÉRIO DAS CIDADES. O Plano Nacional de Habitação-PLANHAB. Disponível em: http://www.cidades.gov.br Acesso em: julho de 2013.

. Lei no 11.977 de 7 de julho de 2009. Presidência da República. Casa Civil. Subsecretaria de Assuntos Jurídicos.

CAMPOS, Andrelino. Do quilombo à favela: A produção do "espaço criminalizado" no Rio de Janeiro. Rio de Janeiro: Bertrand Brasil, 2012.

CARDOSO, A. L. Política habitacional no Brasil: Balanço e perspectivas. Revista Proposta, Rio de 
Janeiro, n'95, p. 6-17, 2003.

CARDOSO, A. L.; ARAGÃO, T. A.; ARAUJO, F. S. Habitação de interesse social: Política ou mercado? Reflexos sobre a construção do espaço metropolitano. In Anais ENANPUR, Rio de Janeiro, 2011.

CARDOSO, A. L.; ARAGÃO, T. A. Do fim do BNH ao Programa Minha Casa Minha Vida: 25 anos de política habitacional no Brasil. In: CARDOSO, A. L. (Org.). O Programa Minha Casa Minha Vida e seus efeitos territoriais. Rio de Janeiro, Letra Capital, 2013.

CARLOS, A. F. A cidade. São Paulo: Contexto, 2009.

FIX, M.; ARANTES, P.F. Como o governo Lula pretende resolver o problema da habitação. Jurdiaí: Human Rights in Brazil, 2009.

FUNDAÇÃO JOÃO PINHEIRO. Déficit habitacional no Brasil. Minas Gerais, 2008.

LAGO, Luciana C. Desigualdades e segregação na metrópole: O Rio de Janeiro em tempo de crise. Rio de Janeiro: Revan/Fase, 2000.

LAGO, Luciana C.; RIBEIRO, Luiz C. Q. A casa própria em tempo de crise: Os novos padrões de provisão de moradia nas grandes cidades. In: RIBEIRO, Luiz C. Q.; AZEVEDO, S. A crise da moradia nas grandes cidades: Da questão da habitação à reforma urbana. Rio de Janeiro: UFRJ, 1996.

MARICATO, E. Autoconstrução, a arquitetura possível. In: MARICATO, H. (Org.). A produção capitalista da casa (e da cidade) no Brasil industrial. São Paulo: Alfa-Omega, 1982, p. 71-93.

Hucitec, 1996.

Metrópole na periferia do capitalismo: ilegalidade, desigualdade e violência. São Paulo:

NAIME, J. A Política de habitação social no governo Lula: Dinâmicas e perspectivas. In: Seminário Nacional Governança Urbana e Desenvolvimento Metropolitano, 2010, Natal, UFRN.

OLIVEIRA, Alfredo C. Tavares; FERNANDES, Nelson da Nóbrega. Marechal Hermes e as (des) conhecidas origens da habitação social no Brasil: O paradoxo da vitrine não vista. In:

OLIVEIRA, Márcio Piñon; FERNANDES, Nelson da Nóbrega (Orgs.). 150 anos de subúrbio carioca. Rio de Janeiro: Lamparina, Faperj, EDUFF, 2010.

RIBEIRO, A. C. Torres. Urbanidade e vida metropolitana. Rio de Janeiro: Jobran Editora, 1996.

Rio de Janeiro (Cidade). Portal Eletrônico da Prefeitura Municipal do Rio de Janeiro). Disponível em: <http://www.rio.rj.gov.br>. Acesso em: 12/05/2013.

Rio de Janeiro. Secretaria Municipal de Urbanismo. Disponível em: HTTP://www.rio.rj.gov.br. Acesso em: 28/11/2014.

ROLNIK, R.; CYMBALISTA, R.; NAKANO, K. Solo urbano e habitação de interesse social: A questão fundiária na política habitacional e urbana do país. Disponível em: http://raquelrolnik.wordpress.com Acesso em: 30/07/2013.

SANTOS JUNIOR, Orlando A. Reforma urbana: Por um novo modelo de planejamento e gestão das cidades. Rio de Janeiro: FASE, 1995.

SANTOS JUNIOR, O. A.; MONTANDON, D. T. Síntese, desafios e recomendações. In: SANTOS 
JUNIOR, O. A.; MONTANDON, D. T. (Orgs.). Os Planos Diretores municipais pós-Estatuto da Cidade: Balanço crítico e perspectivas. Rio de Janeiro: Letra Capital, 2011.

SANTOS, Milton. A urbanização brasileira. São Paulo: Hucitec, 1993.

SINGER, P. O uso do solo urbano na economia capitalista. In: MARICATO, E. (Org.). A produção capitalista da casa (e da cidade) no Brasil industrial. São Paulo: Alfa Omega, 1982, p. 21-36.

VALLADARES, Licia do Prado. Passa-se uma casa: Análise do programa de remoção de favelas no Rio de Janeiro. Rio de Janeiro: Zahar, 1978. 